\title{
Synthesis of C3-C9 Sulfonyl Derivative of Soraphen $A^{*}$
}

\author{
Se Hwan Park, Hyo Won Lee, and Seung-Un Park ${ }^{\ddagger}$ \\ Department of Chemistry, Chunghth National Lniversity, Cheonglu, Chungbuk 361-763, Norea \\ ${ }^{\ddagger}$ Department of Chemistry, Sonkuk Lniversitu, Seoul 143-701, Norea \\ Recened Octoher 13, 2004
}

Key Words : Soraphen. Macrolide, Roush reaction

Soraphen A (1) is an 18 -membered macrolide isolated from myxobacterium Sorongitm Celhulosum. It displays potent antifungal activity against various pathogenic plant fungi because of its highly efficient and specific inhibitory activity on acetyl CoA carboxylase. ${ }^{1.2}$ The structure of soraphen A was well defincd by X-ray crystallographic analy sis. The presence of an unsubstituted phenyl ring and a hemiketal ring constitutes its structural featurc. The first total synthesis of soraphen A was reported by Gicsc in

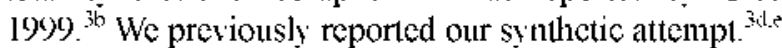

Toward the synthesis of soraphen A. we deliberated the coupling of two fragments 3 and $\boldsymbol{t}$ involving Julia oletination and lactonization (Schenc l). Julia olcfination reaction for trans (C)-Cl0 double bond requires sulfone + with a tetrazole ring. As for this sulfonyl compound we envisioned that the stcreochemical syn-syn-ant relationship along $\mathrm{C} 5$ to $\mathrm{C} 9$ could be achieved using the Roush

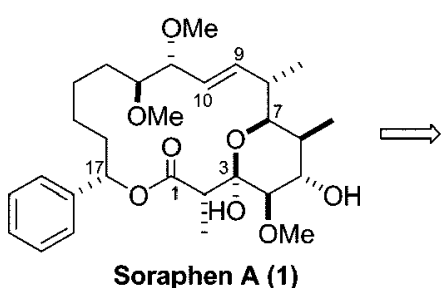

Soraphen A (1)<smiles>C=CCCCCC(OC)C(C=O)OC</smiles>

3

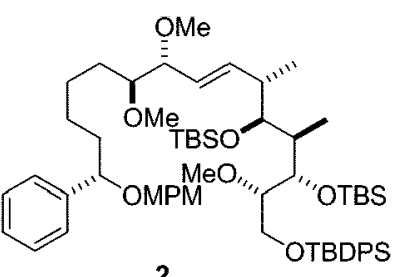

2

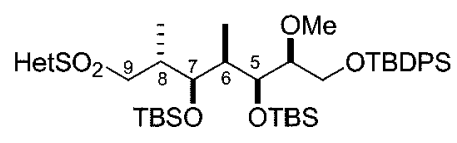<smiles>[R]C=CC(=O)OC1OB(C/C=C\C)OC1C(=O)OCC</smiles>

7<smiles>[R]C(O)C(C)C=C</smiles><smiles>[R]C(O)[C@H](C)C=C</smiles>

8
Scheme 2. Roush Crotylation Reaction for swh- and antiHomoally lic Alcohols.

croylation. ${ }^{4}$ The reaction of $(R . R)$-lartrate ester modificd $(Z)$ - and (E)-crotylboronates 5 and 7 with aldehydes provides s.n- and anti-homoally 1 alcohols 6 and 8 . respectively, with required stereochemistry for C.5-C9 skelcton (Schenc 2). And the following oronolysis of the terminal vinyl group of these internediates would funish the desired products. The resulting retrosynthetic analy sis of the sulfonyl C3-C9 was shown in Scheme 3.

Our synthetic pathway to the C3-C9 sulfonyl derivative according to our retrosynthetic analysis is delineated in Scheme 4. Al first. we considered acctonide of Lglyceraldehy de as a substratc for the Roush reaction. But the necessity of methylation at $\mathrm{C}+$ suggests the preparation of glyceraldehyde 10. which can be casily prepared from Ltartaric acid rather than $L$-ascorbic acid. In order to preparc glyceraldehyde 10. $(R)$-1-(tert-buty ldipheny lsilyloxy)but-3cn-2-ol was prepared from L-tartaric acid by the modification of the procedure reported in the litcrature. $\mathrm{O}$ Methylation of 11 using methỵl iodide and sodium hydride followed by ozonolysis reaction provided aldehy de 10. The

Scheme 1. Retrosinthetic Analysis.

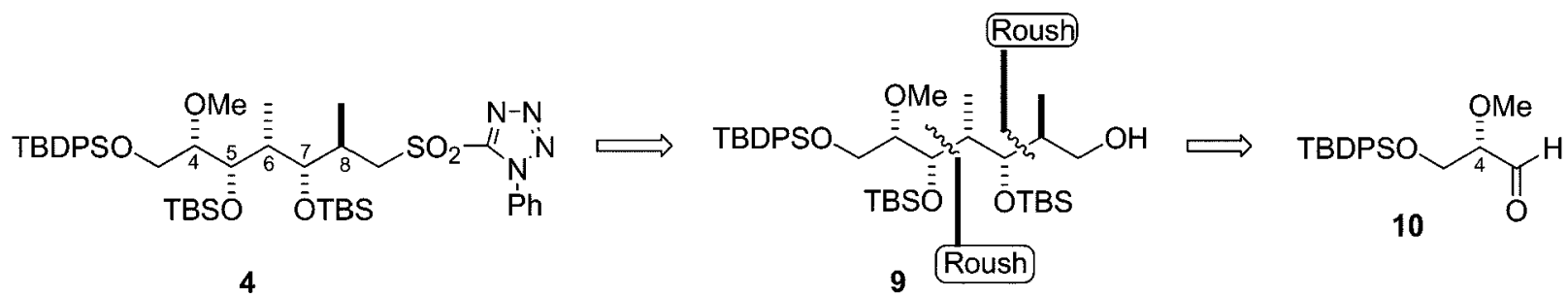

Scheme 3. Retrossunthetic Analysis of C 3-C9 Fragment Using Roush Reaction tor the Control of C5-C8 Stereochemistry.

\footnotetext{
IDedicaled to Prolessor Yong I lae Kim for his distinguished achievements in organic chemistry

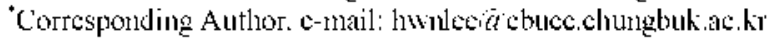




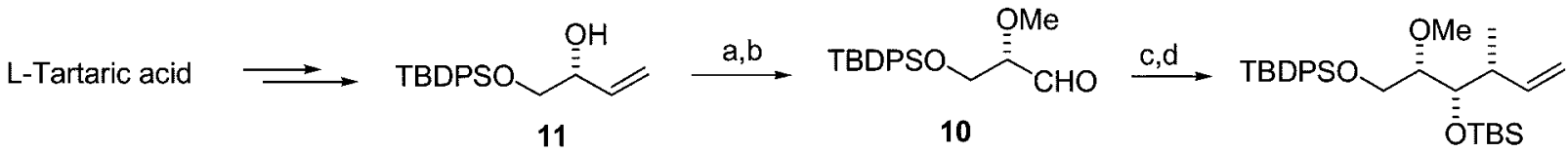

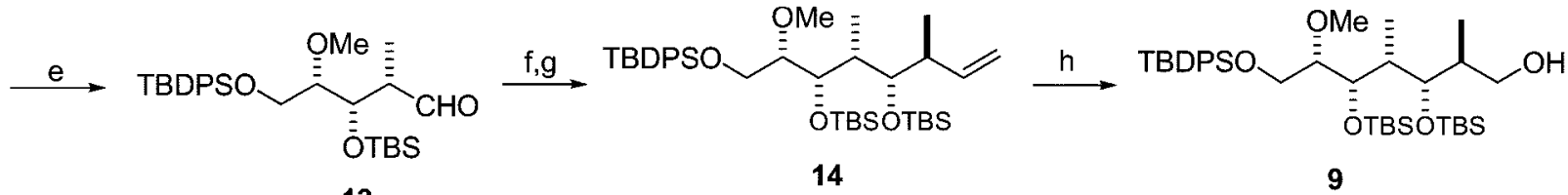

13

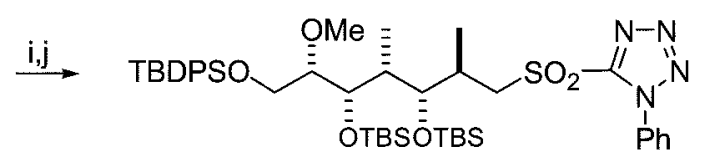

4

Reagents: (a) MeI, $\mathrm{NaH}, \mathrm{THF}, \mathrm{rt}, 3 \mathrm{~h}, 88 \%$; (b) $\mathrm{O}_{3}, \mathrm{MeOH},-78^{\circ} \mathrm{C}$; $\mathrm{Me}_{2} \mathrm{~S}, 80 \%$; (c) 5, 4A MS, toluene, $-78^{\circ} \mathrm{C}, 3 \mathrm{~h}, 78 \%$; (d) TBSOTf, $2,6-$ lutidine, $\mathrm{CH}_{2} \mathrm{Cl}_{2}, 0^{\circ} \mathrm{C}, 2 \mathrm{~h}, 93 \%$; (e) $\mathrm{O}_{3}, \mathrm{MeOH},-78{ }^{\circ} \mathrm{C}$; $\mathrm{Me} 2 \mathrm{~S}, 90 \%$; (f) 7, 4A MS, toluene, -78 " $\mathrm{C}, 3 \mathrm{~h}, 72 \%$; (g) TBSOTf, 2,6-lutidine, $\mathrm{CH}_{2} \mathrm{Cl}_{2}, \mathrm{rt}, 2 \mathrm{~h}, 90 \%$; (h) $\mathrm{O}_{3}, \mathrm{MeOH},-78^{\circ} \mathrm{C}$ : $\mathrm{Me}_{2} \mathrm{~S}, \mathrm{NaBH}_{4}, 0{ }^{\circ} \mathrm{C}, 87 \%$; (i) l-Phenyl-1H-tetrazole-5-thiol, DIAD, PPh, THF, rt, 24 h, 87\%; (i) mepba, $\mathrm{NaHCO}_{3}, \mathrm{H}_{2} \mathrm{O}: \mathrm{CH}_{2} \mathrm{Cl}_{2}(1: 2), 0{ }^{\circ} \mathrm{C}, 80 \%$

Scheme 4. Reaction Pathway to the C3-C9 Fragnent.

reaction of the Roush reagent of $(Z)$-crotylboronate 5 gave the desired syn stereochenistry (sm:anti $=95.5)$. The secondary hydroxy group of the intermediate was converted to $t$-butyldimethylsilyl ether 12 by treatment with $t$ butyldimethylsilyl triflate and 2,6-lutidine in dichloromethane at $0^{\circ} \mathrm{C}$. The ozonolysis on the terminal vinyl group of 12 furnished aldehyde 13 . which was consequently subjected to the Roush reaction using $(E)$-crotylboronate 7 to obtain ant $i$-product $($ antisyn $=88: 12$ ). This compound was converted to $t$-butyldimethylsilyl ether 14 by treating with $t$-butyldimethylsilyl triflate and 2.6-lutidine. The next step along the sequence was the preparation of alcohol 9. which is the precursor of the sulfone. Thus the ozonolysis intermediate of 14 was reduced with sodium borohydride to provide alcohol 9. Preparation of the tetrazole thioether from 9 using diisopropyl azodicarboxylate (DIAD) and tripheny phosphine. and subsequent oxidation with mopba finally yielded the desired sulfone 4 .

In summary, we have achieved the synthesis of the C3-C9 fragment of soraphen A (1) by recurring use of stereoselective Roush crotylation and subsequent ozonolysis as key transformations.

Acknowledgement. This work was supported by Chungbuk National University Grant in 2004.

\section{References}

1. (a) Bedorf. N.: Schomburg. D.: Gerth. K:: Reichenbach. H.: Höfle. G. Liebigs Am. Chem. 1993. 1017-1021. (b) Gerth. K.: Reichenbach, H.; Bedorf, N.: Irschik. H.; Hötle, G. J. Antibiotics 1994. $47,23-31$

2. GBF $\mathrm{mbH}$ and Ciba-Geigy . $\mathrm{G}$. EP $282455 \mathrm{~A} 2$ (Chenical Abst: 1988. $111.132597 \mathrm{v}$.

3. (a) Abel. S.: Faber. D.: Hüter. O.: Giese. B. Angew. Chen. Int. Ed. Engl. 1994. 33. 2466-2468. (b) Abel. S.: Faber. D.: Hüter. O.: Giese. B. Swmhesis 1999, 188-197. (c) Gurjar, M. K.: Mainkar. A. S.: Srinivas, P. Tetahedron Lett 1995. 36. 5967-5968. (d) Lee. H. W. Kim. Y. J. Bull. Korean Chem. Soc. 1996. 17. 1107-1108. (e) Lee. H. W: Lee. I.-Y. C.: Kim. Y.-S.: Park. S.-U. Bull. Koream Chent. Soc. 2002. 23. 1197-1198. (f) Loubinoux. B.: Sinnes. J.-L.: O'Sullivant. A. C.: Winkler. T. Heht Chm. Acta 1995. 78. 122-128. (g) Loubinoux. B.: Sinnes, J.-L:; O'Sullivan, A. C.: Winkler. T. Tetrahedron 1995, 51, 3549-3558. (h) Loubinoux. B. Simes. J. L. OSullivan, A. C.J. Chem. Soc. Perhin Trans. 1 1995, 51.521525. (i) Loubinoux. B.: Sinnes. J.-L.: OSullivant. A. C.: Winkler. T. J. Org Chem. 1995. 60.953-959. (j) Schummer. D.: Tahn. T.: Höfle. G. Liebigs .Am. 1995. 803-816. (k) Hötle. G.: O'Sullivant. A. C.: Rils, G.: Sutter, M.: Winkler. T. Tetrahedon 1995. 51. 3159-3174. (1) Cao, Y: Eweas. A. F.: Donaldson, W. A. Tetrahedron Lett 2002, 43. 7831-7834.

4. Roush. W. R: Hoong. L. K.: Palmer. M. A.: Straub. I. A.: Palkowitz. A. D. J. Ong Chent 1987.52.4117-4126.

5. (a) Blakemore. P. R.: Cole. W. J.: Kocienski. P. J.: Morley. A. Sintett 1998, 26-28. (b) Kang, S. H.; Hwang. Y. S.; Lee. H. S Bull. Korean Chem. Soc. 2002, 23, 1195-1196. 